\title{
New Iridoviruses In Portuguese Wild Fauna
}

A. P. Alves de Matos***, M. F. Caeiro*, F. Vale***, M. T. Rebelo*, M. C. Proença*****, F. Morgado***** and R. Marschang $* * * * * *$

*Centro de Estudos do Ambiente e do Mar (CESAM) - Faculdade de Ciências da Universidade de Lisboa, Campo Grande, 1749-016, Lisboa, Portugal

** Centro Hospitalar de Lisboa Central - HCC, Anatomia Patológica, R. da Beneficência 8, 1069166 Lisboa, Portugal

*** Faculdade de Engenharia, Universidade Católica Portuguesa, Lisboa, Portugal

**** Laboratório de Óptica, Lasers e Sistemas, Faculdade de Ciências da Universidade de Lisboa, 1749-016, Lisboa, Portugal

***** CESAM, Centro de Estudos do Ambiente e do Mar, Universidade de Aveiro, Campus

Universitário de Santiago, 3810-193 Aveiro, Portugal

****** Institut für Umwelt und Tierhygiene, Hohenheim University, Garbenstr. 30, 70599

Stuttgart, Germany

Heterotermic vertebrates are hosts of a variety of iridoviruses, many with recognized economical importance for aquaculture and with a role in the decline of amphibian populations, and others with no known disease associations. These include members of the Lymphocystisvirus, Magalocystisvirus and Ranavirus genera [1].

Erythrocytic infections of reptiles, amphibians and fish with large icosahedral iridovirus-like viruses were detected in the beginning of the XXth century by light microscopy, since they produce large cytoplasmic inclusions in the infected cells (Figure 1) [2,3]. Our work has confirmed the viral nature of the inclusions (Figure 2) and identified 14 new host species worldwide [4, 5]. Our ultrastructural results detected significant morphological variations among the new viruses that suggest that it is a widespread and diverse group of potential related viruses [5]. Recent data on the sequence of a conserved region of the DNA polymerase gene from our work in Lacerta monticola and the work of Weehlan in a snake erythrocytic virus from the USA, gave a first indication that these viruses are related and probably represent a new genus of the Iridoviridae [6].

Experimental infection data from our studies indicate that the erythrocytic viruses can cross species barriers and may infect other cell types in the laboratory. Thus, although erythrocytic virus infections have seldom been associated with disease, their pathogenic potential may have been underestimated [7]. The infected lizards from Portugal live in mountain areas and the infections, which may reach a prevalence of $10-40 \%$ of the animals in some populations, follow a seasonal distribution, suggesting the presence of still unidentified vectors [8].

Isolation of these viruses has never been achieved, although several attempts have been made by our group and others. During these attempts, a ranavirus very similar to the ranavirus type species FV3 has been isolated from Lacerta monticola (Figure 3) [6]. Other ranaviruses, pathogenic for Triturus marmoratus and Triturus boskai, were isolated by us from diseased animals in the Peneda-Gerês National Park [9].

\section{References}

1. Williams T. et al., Adv Virus Res 65: 173-248, 2005

2. Chatton E. and Blanc G., C R Soc Biol 77: 496-498, 1914

3. França C., Arch Inst Bacteriol Camara Pestana 3: 229-238, 1912

4. Paperna I. and Alves de Matos A.P., Ann Parasitol Hum Comp 68: 11-23, 1993

5. Alves de Matos A.P. and Paperna I., Ann Parasitol Hum Comp 68: 24-33, 1993

6. Alves de Matos A.P. et al., Microsc Microanal 17: 101-108, 2011

7. Alves de Matos A.P. et al., Intervirology 45: 150-159, 2002 
8. Alves de Matos A.P. et al., EMC 2008. Vol. 3. Life Science, pp 103-104. Springer Verl., 2008

9. Soares C. et al., Froglog 56: 1, 2003
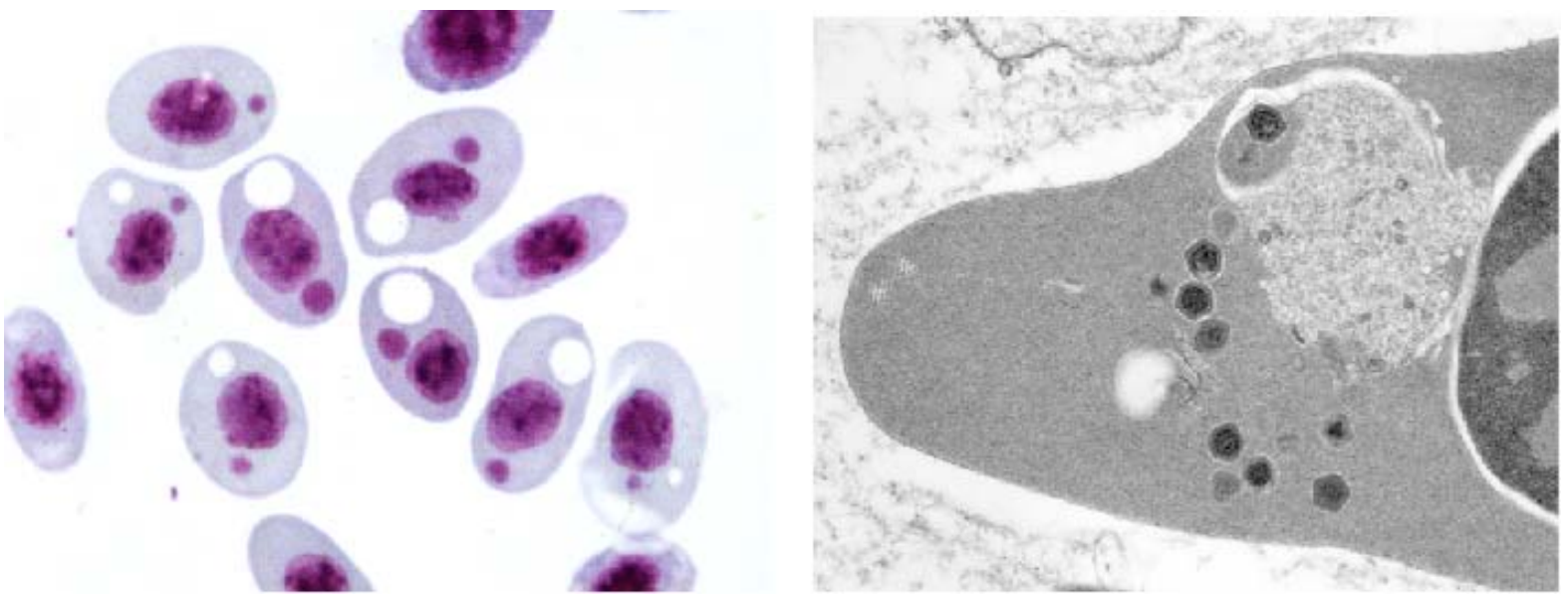

Figure 1. Cytoplasmic inclusions in Giemsa-stained blood smears from an Australian infected gecko (Ptyodactylus hasselquistii). Figure 2. Electron microphotographs of the cytoplasmic inclusions of infected erythrocytes, showing the associated large icosahedral virions.

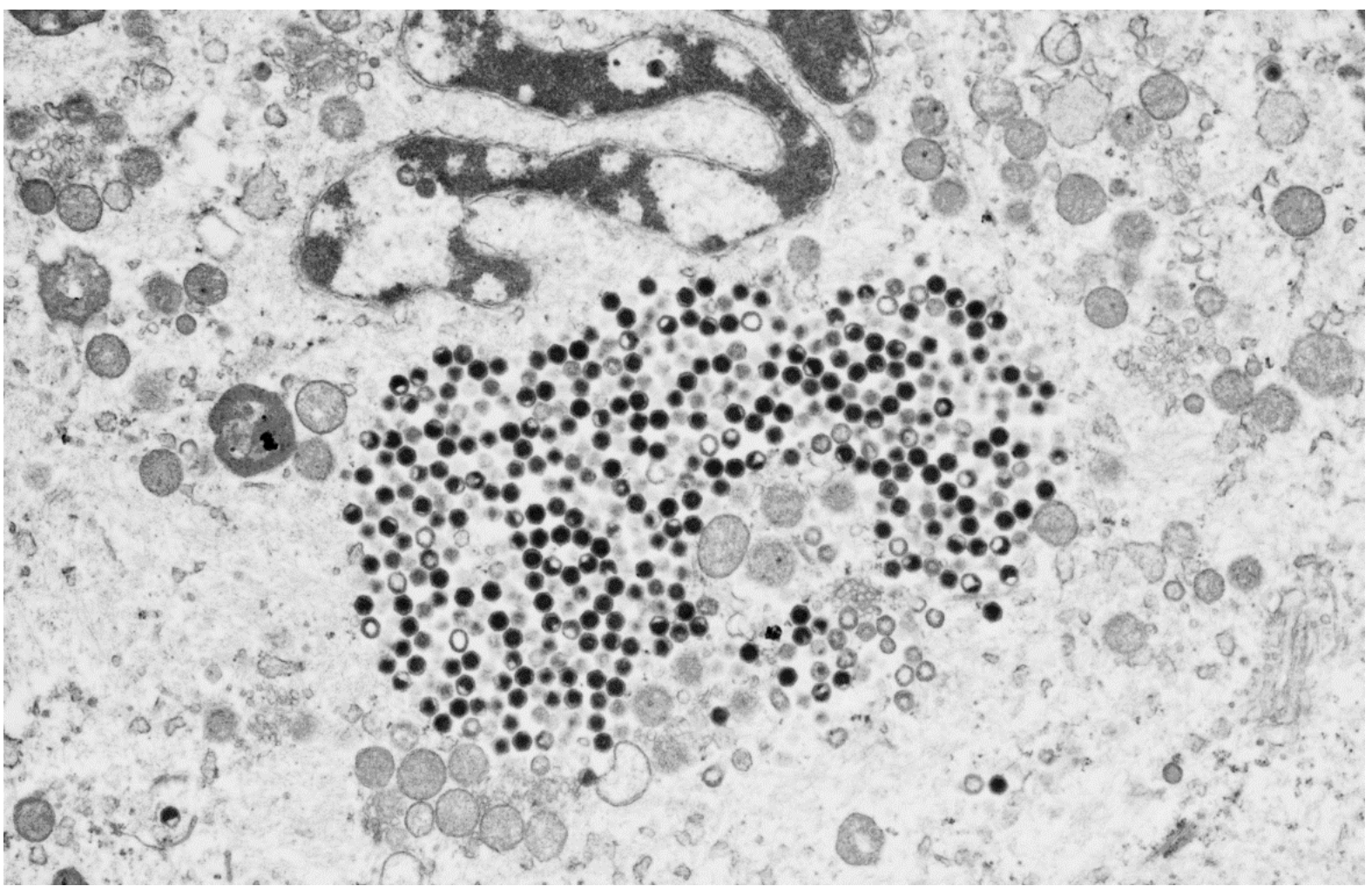

Figure 3. Ranavirus from Lacerta monticola isolated in Vero cells. The image shows an accumulation of virions in the cytoplasm. 